that it would be practicable in an average year thus to supply a demand three times as great as the present demand in the whole of Ireland for electricity, and has recommended and shown the economy of linking up this supply to all important towns and cities ; utilising existing steam-electric stations to supply current when, owing to drought, one summer's flow of the rivers is too far below the average summer flow. The combination is like that at Chester, but on a much larger scale.

Suppose we allocate part of each of the rivers Shannon and Erne to the manufacture of carbide and of nitrogen fertilisers and operate this plant as fully as the flow of water prrmits; with an average output we could make in a $;$ ear fertilisers containing 20,000 tons of nitrogen. Each of these works would be of the size recommended as economical by the Nitrogen Products Committee of the Ministry of Munitions.

It is not definitely known how much nitrogen fertiliser can be utilised within Ireland; but there are markets for carbide and for nitrogen fertilisers outside Ireland, so any excess over home requirements could be exported at a profit.

The nitrogen in various compounds used in a year in the world amounted to 694,600 tons ${ }^{2}$ pre-War and I,2 I9,000 tons post-War (I9I9). There is nothing excessive in recommending fixation in Ireland of 3 per cent. of the world's annual pre-War consumption of nitrogen.

There would be work throughout the year, but more people employed at the chemical works in winter-time

\footnotetext{
2 American Electro-Chemical Society's Proceedings, Volume 34.
}

than in summer. It is well known that about 10,000 workers leave Ireland every summer to do farming in Scotland and England and return to their more economical life in Ireland during the winter-time. For some of those there would be thus provided winter work in their own country; while, of course, there would be employment throughout the year for an appreciable number.

There are nitrogen fixation plants near Niagara and at various other places in the world. About half of the pre-War consumption of nitrogen was in the form of native nitrate of soda. Among the many important applications of water-power, the one in Tasmania, where the Electrolytic Zinc Co. of Australasia, Ltd., utilises 30,000 horse-power from the Tasmanian Government Plant for the preparation of high-grade zinc, is worthy of especial mention.

More attention should be paid to the selection of industries that require large amounts of power, and to their establishment at sites where suitable water-power is available. We cannot recall too often the history of Niagara's development. Before electricity was a commercial form of energy, capital was invested (during the years 1853 to $186 \mathrm{I}$ ) in making provision for direct water-power; in $\mathrm{I} 86 \mathrm{I}$ it was ready, but it ran to waste for ten years before the first consumer arrived in $187 \mathrm{r}$. It was not until 1894 (forty-one years after the commencement referred to) that a profitable amount of power was utilised. Water-power is the cheapest form of energy when fully utilised twentyfour hours in the day.

\title{
Obituary.
}

\section{Prof. J. D. VAN DER WAals.}

W ITH Johannes Diderik van der Waals, who died on March 8 at Amsterdam, at eighty-five years of age, one of the great figures in the history of modern physics and physical chemistry has passed away. His thesis on the continuity of the liquid and gaseous state was a revelation in the study of fluids, the remembrance of which was to glorify the golden jubilee of his doctorate next June, and after establishing it he continued for some forty years to apply his efforts to the same subject, marking the steps of his success by further brilliant discoveries. When the Nobel Institute honoured this lifework, van der Waals was still occupied rounding off the comprehensive views science owed to him. For about half a century he was in the front of the workers in the domain he had opened. In the ten years which separate us now from then his forces began to give way, and later bodily and mental sufferings, borne with modest resignation, set in. At last, only short visits allowed us to show to the venerated and beloved friend, whose heart we felt remained unchanged, what he had done for us.

Van der Waals was born on November 23, I837, at Leyden. He was a self-made man who took advantage of the opportunities offered by the University which he later honoured by his curatorship. It was not until he was thirty-six years of age that he wrote his thesis. With it he himself opened the period of Dutch science, which his elder friend Bosscha and he hoped to be one of the results of secondary education.
In 1877 , van der Waals became a professor at Amsterdam, and began to exert his great influence on the development of Dutch physics. One of the characteristics of his highly admired teaching was the introduction of Gibbs's great work to the chemists. I vividly remember as an example of it how Bakhuis Roozeboom, to whose first experiments the Leyden physical laboratory had been in the position to give some help, obtained results, which were inexplicable until van der Waals came to give him the key to it in Gibbs's doctrine of phases, his deep insight clearing the way for Roozeboom's brilliant work on the phase rule.

Very much was done by van der Waals for the Royal Academy of Sciences at Amsterdam. For twentyfour years he was the soul of the Board, and in 1896 he even accepted the secretaryship of the Academy, a post which he filled until Igr2. Here as everywhere else he showed a never-failing unselfishness and high conception of duty. We owe to him the modern form of the Proceedings and their English translation, which he directed, both with an incomparable energy. The great efforts he bestowed on these periodicals have been well rewarded by the effect their stimulating influence had on Dutch science.

The scientific work of van der Waals forms a monumental whole of a special style. Characteristic of it is the intuition by which he introduced happy simplifications and approximations leading to a high degree of qualitative agreement of his theories with Nature, which in the case of the law of corresponding states rose even to a surprising quantitative approximation. 
The first idea of the image of the fluid state which was gradually developed by van der Waals came to him when he combined the kinetic theory of gases with the determination of the cohesion in Laplace's theory of capillarity. With the aid of very happy approximations he built up the kinetic theory of the fluid state. Such a simplification gave in the first place the calculation of a molecular pressure which represents the cohesion, and the result of the calculation led him to the profound conception that the molecules of the gaseous and the liquid state are identical and exert identical forces. Secondly, he accepted as by inspiration an exceedingly appropriate form for what would be the outcome of the calculation of the kinetic pressure at higher densities. The simple equation of state which he obtained in this way reproduced the well-known diagram of Andrews-Thomson, as the representation of a series of stable and unstable states of mechanical equilibrium. It gave a deeper insight into the continuity of the liquid and gaseous state as well as a luminous explanation of the critical phenomena. It stood even the crucial test which van der Waals only with apprehension undertook to apply to it; that is, the calculation of the critical data of carbon dioxide of Andrews from the deviations from Boyle's law according to Regnault. Finding correct values for these meant a great discovery. The various thermal properties of fluids treated until then in different chapters of physics proved now to be at least approximatively contained in a single equation with only two specific constants, the volume and the attraction of the molecules, their molecular weights being given by their composition. Later researches have proved, more and more, the greatness of the genius which led van der Waals to his equation of state. Even now it is the most appropriate one to discuss qualitatively the properties of fluids.

Directly from this can be derived the second great discovery of van der Waals, namely, that it is only necessary to introduce the reduced values of volume, temperature, and pressure obtained by dividing the values of these variables by their critical values into the equation of state, to reduce this equation to the same equation for all substances. Simple as this substitution is, it took seven years before it was arrived at, and then only by van der Waals himself, who had been wrestling for a long time with the explanation of the deviations between his equation of state and reality. He had followed many false tracks in order to find some regularity in the deviations of the different substances, and had reached the conviction that to compare substances they have to be considered in corresponding states; that is, at the same values of the reduced variables. At that moment he found the law of corresponding states. Its scope is far wider than that of the equation of state. It involves the bold idea that the thermal properties of all substances can be derived from those of a single one simply by numbers of proportionality; and, what is marvellous, the law approximates more closely to Nature than the equation from which it is derived. How much I was under the influence of its great importance as much as forty years ago may be best judged by my taking it then as a guide for my own researches. It has had a great effect on the work of liquefying the permanent gases (in his thesis van der Waals predicted that air had to be cooled below $-\mathrm{I} 58^{\circ} \mathrm{C}$. to be liquefied, which has proved nearly correct) and of attaining the nadir of temperature.

This cannot be better illustrated than with the words of our deeply mourned Sir James Dewar in a letter to me, expressing that van der Waals was "the master of us all," "whom we cannot honour too much." All substances, except for small differences, appear in the light of the law of corresponding states, as van der Waals expresses it, as individuals of the same kind. He liked to direct attention to the fact that his friend Dewar had proved that, taking temperature as a measure, hydrogen was, according to his prophecy, a dwarf. To read to van der Waals a report of the experiments which proved that helium, though a very small dwarf, was yet well shaped, was a happy moment in my life, especially as the report showed the profit derived from van der Waals' law of corresponding states and at the end referred to his words that " matter would always show attraction."

As all normal substances are almost copies of the same model, van der Waals was anxious to bring his equation of state in closer approximation to this general model and to understand the differences between the various substances. To his pondering on the influence of association into double molecules on the deviations, we owe his theory of binary mixtures, which covers a yet vaster and more varied field than his previous discoveries. It is especially this theory to which, in connexion with the beautiful work of our deeply mourned Kuenen, I owe the strong ties which united me to van der Waals. For many years I went to his study at Amsterdam for a "monthly private course," that is, a consultation on the Leyden work, and I found van der Waals always at his table filled with papers, with the portrait of his wife, who died at an early age, on the chair in front of him. In these hours it often occurred that from an unpublished calculation he could rightly predict some error to be found in the diagrams of the experiments; and it is from them that I have got an idea of the amount of work from which his genius came to his intuitions.

It would occupy too much space here to refer in detail to the work of van.der Waals, which groups itself around these three great discoveries. I can only point out that he tried to combine the theory of specific heats with that of the equation of state, and that in the end he was occupied with the very interesting problem of the influence of the conglomeration of greater number of molecules; that of quasiassociation. Rounding off in this way the chapter he wrote in the history of science, he gave us, at the same time, a glimpse of that chapter which the next generation has to write, containing a rational application of quantum considerations in van der Waals' theory of the fluid state.

Not less than the extraordinary intellectual gifts which made possible his great life work, his friends admired his severe culture of the ideal and his noble character. We remember the pious heart, in whose friendship we rejoiced, and with a feeling of deep sorrow at the loss of his presence, we give him here the tribute of our profound gratitude.

H. Kamerlingh OnNes.

NO. 2792 , VOL. 1 I I ] 